\title{
ENVIRONMENTAL AND STRUCTURAL RISK ASSESSMENT OF LONG OPERATED VITRIFIED CLAY SEWERS
}

\begin{abstract}
Investigations have been presented on the type, extent and frequency of operational and maintenance as well as structural linear and spot defects that occurred in long operated vitrified clay sewers, which are the most often used in sanitary sewer systems. The causes of the defects have been determined and summarized in five groups. Two sewer failure probability matrices taking into account the impact of all the defects analysed in terms of environmental and structural hazards have been proposed. Numerical values determined for each element of the two matrices allow allocating the sewers into five probability of failure categories. The proposed method contains the consequences of failure of matrix of sewer, and finally two matrices of risk for environmental and structural safety. The elaborated method enables prioritization of sewers in terms of environmental and structural hazards from those of the highest to those of the lower risk, which allows efficient sewer failure management and may be used for planning the sewer trenchless maintenance and rehabilitation.
\end{abstract}

\section{INTRODUCTION}

Damages and leaky sewers are the cause of different environmental and structural hazards $[1,2]$. This study aims to:

- determine what types of defects occur in vitrified clay sewers, how often they are appear, how severe they are, and what are the causes of defects,

- propose a method of determining sewer failure risk, based on closed circuit television video (CCTV) inspections.

Underground infrastructure pipes fail $[3,4]$ either with time due to aging, or prematurely, before they attain their design service life, due to design faults, faulty workmanship or improper operation and maintenance (O\&M).

${ }^{1}$ Faculty of Environmental, Geomatic and Power Engineering, Kielce University of Technology, al. Tysiąclecia Państwa Polskiego 7, 25-314 Kielce, Poland, e-mail address: emkulicz@tu.kielce.pl 
Consequences of failure of sewer pipelines can be in most cases very serious. Sewer pipe failures can be serious when the consequences brought by typically structural defects lead to the collapse of pipes and sinkhole. This might lead to traffic accidents or failure of others pipelines and objects in the vicinity.

Typically O\&M defects causes an overflow of sewers which in turn may result in flooding and contamination of neighbouring areas. Groundwater infiltration (often with soil) into the leaky sewers may lead to the lowering of the water table and result in the loss of vegetation, land subsidence, increased amount of sediment in the sewers and hindering the operation of pumping stations and biological treatment plants. Municipal and industrial wastewater exfiltration from leaky sewers into the groundwater could cause contamination of soil and groundwater. Improperly connected storm water drains to the sanitary sewers cause wrong operation of the municipal sewage treatment plants and drains of improperly connected sanitary sewers to the storm water could cause contamination of the natural receivers.

Considering these factors, the evaluation of the causes of failure in sewer pipelines seems to be warranted. This paper is an example of such an analysis.

The structural and O\&M defects likely to occur in sewer pipes are summarized in European norm EN 13508-2 and American guidelines NASSCO's PACP. This analysis refers only to those defects that are crucial to serviceability and environmental hazards of the sewers or their structural safety. Zayed et al. [2] and Veldhuis et al. [5] proved the importance of inquiry into the latter. Kuliczkowski et al. justified appropriateness of separating the defect issues related to structural safety of sewer pipelines from those relating to serviceability and environmental hazards [3]. Several studies have served as the basis for the development of sewer defect matrices. Kuliczkowska assessed 10 different defect classifications [6], while the American standardization program NASSCO's PACP and European reports [7, 8] related to vitrified clay pipe examination and the evaluation of the defect size-failure probability relationship. Two matrices have been developed, O\&M defects matrix $\mathbf{P}^{E}$ and structural defects matrix $\mathbf{P}^{S}$. Elements of these matrices contain lower limit numerical values defining the size of particular defects for each of the proposed categories of sewer failure probability.

Numerical values allocated to all the elements of both matrices allow determining the category of the probability of failure caused by each of the defects detected during the CCTV inspections. The proposed method contains the matrix $\mathbf{K}$ of consequences of sewer failure and finally two matrices of environmental $\left(\mathbf{R}^{E}\right)$ and structural $\left(\mathbf{R}^{S}\right)$ sewer failure risk. Sewer failure risk matrices are a useful tool in prioritization of trenchless rehabilitation works [9] or by adequate maintenance-repair procedures.

Analysis of the types and causes of defects is particularly important considering that vitrified clay pipes have been used to build sewer pipelines since the mid-19th century. According to Berger and Falk, vitrified clay pipes make up $42 \%$ of all existing sewer pipelines in Germany, likewise in other countries. According to Berger and Falk [8], the total length of sewers in Germany is estimated to be approximately $600000 \mathrm{~km}$ 
(540 $723 \mathrm{~km}$ in 2007), thus sewer technical condition issues are the concern of about $240000 \mathrm{~km}$ of sewers in Germany alone. Similar ratio of vitrified clay pipes in the material structure of sanitary sewers in service exists in Poland, where in some cities vitrified clay pipes account for more than half of the operating sewers, while, for example in Vancouver in Canada it is $79.26 \%$ [10] and 95\% [11] in Phoenix in USA.

\section{SCOPE OF STUDY AND RESULTS OF CCTV INSPECTIONS}

The method of CCTV inspections was first used in Europe in Germany in 1958. In Poland, the first CCTV camera for sewer inspection was built in 1969. Kielce University of Technology was the first university in Poland to conduct regular CCTV surveys of sewers in many cities throughout the country. Since 1991, more than $200 \mathrm{~km}$ of sewer pipe lines have been inspected made of various materials (concrete, reinforced or prestressed concrete, vitrified clay, asbestos cement, steel, cast iron, polyvinyl chloride $(\mathrm{PVC})$, polyethylene (PE), polypropylene (PP), and glass-reinforced plastic (GRP)).

This study summarizes the results of the analysis of $14897 \mathrm{~m}$ of vitrified clay sewer pipelines randomly chosen in 19 Polish cities. Sixty six inspections were conducted, diverse in terms of the city, street and pipe diameter. 422 sections of the pipelines have been inspected. The diameters of the sewer pipes varied from DN 200 to DN 500.

Types of defects observed during the CCTV surveys of the sewer pipelines were grouped in two categories: O\&M defects hindering serviceability of the sewer and posing environmental hazards, coded as e $01, \mathrm{e} 02, \ldots \mathrm{e} 10$ and defects directly affecting structural integrity of the pipes, coded as $\mathrm{s} 01, \mathrm{~s} 02, . . \mathrm{s} 06$ :

e01 - movable deposits,

e02 - solid deposits,

$\mathrm{e} 03$ - roots of the tree growing into a sewer,

e04 - lateral intruding into a sewer,

e05 - other external pipeline built through the sewer wall or improper connection for example connection of sanitary laterals into storm water drains,

e06 - infiltration of groundwater into a leaky sewer,

e07 - sealing gaskets intruding into a sewer,

e08 - post infiltration encrustation,

e09 - radial displaced joint,

e10 - longitudinal displaced joint,

$\mathrm{s} 01$ - abrasion of the pipe bottom,

s02 - longitudinal cracks,

s03 - circumferential cracks,

s04 - diagonal cracks,

s05 - missing sewer wall pieces,

s06 - rigid sewer deformation or collapse. 
Operational defects such as bottom deposits, ingrowing tree roots, groundwater infiltration, etc., contribute to the flooding of sewers and laterals and often cause the sewage overflow into the immediate area. Soil destabilization due to particles of soil being flushed in with the groundwater infiltrating into the sewers results in the collapse of the sewers and of the ground located directly above them. Prevention strategy used to prevent O\&M defects is less costly compared with that of structural defects and includes sealing, cleaning, removal of roots, etc.

Structural defects such as bottom abrasion, missing wall pieces, fractures, etc., reduce the sewer factor of safety leading to the collapse of the sewer. Possible preventive measures would include choosing appropriate methods of trenchless rehabilitation or replacement of the sewers. Linear defects (Table 1) are presented as a ratio of the length of deteriorated sewer pipelines to their total length. Spot defects (Table 2) are presented in numbers per $100 \mathrm{~m}$.

Table 1

Summary of linear defects in vitrified clay pipelines inspected at Kielce University of Technology

\begin{tabular}{|l|c|}
\hline \multicolumn{1}{|c|}{ Linear defects } & $\begin{array}{c}\text { Length of sewers with linear defects } \\
{[\%]}\end{array}$ \\
\hline e01 - movable deposits & 60.23 \\
\hline s02 - longitudinal cracks & 1.96 \\
\hline e02 - solid deposits & 0.91 \\
\hline s06 - rigid sewer deformation or collapse & 0.33 \\
\hline s01 - abrasion of the pipe bottom & 0.01 \\
\hline
\end{tabular}

Table 2

Summary of spot defects in vitrified clay pipelines inspected at Kielce University of Technology

\begin{tabular}{|l|c|}
\hline \multicolumn{1}{|c|}{ Spot defects } & $\begin{array}{c}\text { Frequency of spot defects } \\
\text { in sewers [numbers/100 m] }\end{array}$ \\
\hline e09 - radial displaced joint & 17.95 \\
\hline e10 - longitudinal displaced joint & 12.15 \\
\hline e08 - post infiltration encrustation & 7.82 \\
\hline e03 - roots of the tree growing into the sewer & 3.99 \\
\hline s04 - diagonal cracks & 2.01 \\
\hline e06 - infiltration of the groundwater into the leaky sewer & 1.48 \\
\hline s05 - missing sewer wall pieces & 1.28 \\
\hline e04 - a lateral intruding into the sewer & 0.72 \\
\hline s03 - circumferential cracks & 0.69 \\
\hline e07 - sealing gaskets intruding into sewer & 0.16 \\
\hline $\begin{array}{l}\text { e05 - other external pipeline built through sewer wall } \\
\text { or improper connection for example connection } \\
\text { of the sanitary laterals into storm water drains }\end{array}$ & 0.01 \\
\hline
\end{tabular}


Linear defects occurring most frequently (Table 1) included movable deposit e01 and longitudinal cracks s02. Spot defects (Table 2) observed most frequently included radial e 09 or longitudinal displaced joints e 10 , post infiltration encrustation e08 and ingrown roots $\mathrm{e} 03$.

\section{CAUSES OF DEFECTS}

The investigations conducted at Kielce University of Technology revealed that the causes of defects in the vitrified clay sewer pipelines can be collated in five groups:

Design faults. Adopting soil and traffic loads smaller than the actual ones, or hydraulic calculation errors (longitudinal slope too small or cross-section too wide).

Improper materials and material aging. Use of ineffective sealing material, for example bitumen dipped hemp and cement mortar, use of pipes with load capacity lower than the recommended by the standards, use of low-quality seals or low-quality material.

Faulty workmanship. Careless performance or embedment (e.g., pipe hit with an excavator spoon), worse-quality bedding material, lower embedding angle or improper soil compaction, careless connection of laterals or faulty connections, for example sanitary laterals connected to storm drains and vice versa, the presence of other pipes such as gas or water pipes in the sewer.

Incorrect $O \& M$. Failure to conduct regular cleaning or incorrect cleaning, use of improper cleaning equipment, or introduction of wastewater that fails to meet the standard requirements in terms of chemical composition or temperature.

External factors during the sewer service live. Increase live and dead loads due to, e.g., building an embankment or expanding the road surface to stretch over the sewer, higher groundwater table.

The defects observed in the sewer pipelines can be additionally divided into primary and secondary ones. Primary defects initiate improper sewer performance and, if not eliminated, lead to permanent secondary defects such as ground water infiltration (e06), which occurs when the ground water level exceeds the level of the sewer bottom, and the sewer is leaky due to: sealing rings intruding into sewer (e07), radial (e09), or longitudinal displaced joints (e10), longitudinal (s02), circumferential (s03), or diagonal cracks (s04), missing sewer wall pieces (s05) and pipe collapse (s06).

\section{CATEGORIES OF PROBABILITY OF THE SEWER FAILURES}

The factor of safety of a vitrified clay sewer pipe in long-term service can be determined after its field measurements have been completed, for example in accordance with [12]. The sewer has to be excavated, the type and angle of the pipe embedding have to be determined, parameters of the soil surrounding the pipe have to be measured, 
then the load capacity has to be established in laboratory tests on a segment of the pipe, and finally static calculations have to be made. The procedure is costly and likely to result in disturbance on account of the trench digging. Yet its basic advantage is the possibility for accurate determination of the sewer safety factor. Sewer pipelines in urban areas are tens to hundreds kilometers long, thus evaluation of their structural integrity based on results of CCTV survey seems to be a rational solution. Analyses described in $[1,6]$ and in other reports make it possible, considering state of the art on the effects of type and size of the observed defects, to determine the category of probability of sewer structural failure using CCTV technology. Five categories of sewer failure probability [3] are usually recognized: very unlikely, unlikely, somewhat likely, likely, highly likely. The method proposed by the author of this paper and presented below allocates sewers to one of these categories taking into account the safety criterion.

The matrix $\mathbf{P}^{S}$ of categories of structural failure probability for the analysed defects is proposed:

$$
\mathbf{P}^{\mathrm{S}}=\left|\begin{array}{cccccc}
p_{1,1}^{S} & p_{1,2}^{S} & \ldots & p_{1, j}^{S} & \ldots & p_{1, n 1}^{S} \\
p_{2,1}^{S} & p_{2,2}^{S} & \ldots & p_{2, j}^{S} & \ldots & p_{2, n 1}^{S} \\
\ldots & \ldots & \ldots & \ldots & \ldots & \ldots \\
p_{i, 1}^{S} & p_{i, 2}^{S} & \ldots & p_{i, j}^{S} & \ldots & p_{i, n 1}^{S} \\
\ldots & \ldots & \ldots & \ldots & \ldots & \ldots \\
p_{m 1,1}^{S} & p_{m 1,2}^{S} & \ldots & p_{m 1, j}^{S} & \ldots & p_{m 1, n 1}^{S}
\end{array}\right|
$$

where: $p_{i, j}^{S}$ is the element of matrix $\mathbf{P}^{S}$ containing lower boundary values that define the size of an $i$-th defect (described above as $\mathrm{s} 01, \mathrm{~s} 02, \ldots \mathrm{s} 06$ ) expressed in $\mathrm{mm}, \mathrm{cm}^{2}$ or percent for the $j$-th category of the sewer structural failure probability, $m 1-$ the number of $i$-th defects having a direct impact on the structural failure probability of sewer pipes ( $m 1=6$ in this study), $n 1$ - the number of $j$-th categories of the probability of structural failure considered in groups from the lowest to the highest defect severity.

In the matrix $\mathbf{P}^{S}, n 1=5$ categories of structural failure probability were adopted:

- category of probability $1,(j=1)$, very unlikely (acceptable structural condition, failure unlikely in the foreseeable future),

- category of probability $2,(j=2)$, unlikely (minimal failure probability in the short term but potential for further deterioration, sewer unlikely to fail for at least 20 years),

- category of probability $3,(j=3)$, somewhat likely (failure unlikely in the near future but further deterioration likely, sewer may fail in 10-20 years),

- category of probability $4,(j=4)$, likely (failure likely in the near future, sewer will probably fail in $5-10$ years),

- category of probability $5,(j=5)$, highly likely (sewer has failed or will likely fail within the next five years). 
Numerical values of elements of the matrix $\mathbf{P}^{S}$ were determined based on the author's study [6] and the allocations of defects to one of several classes (usually four, five or six classes) proposed by British [1], Danish [13], German [7], Dutch [14], and American NASSCO's PACP authors or societies. For example, for defect $i=4$, i.e., diagonal cracks, expressed in $\mathrm{mm}$, vector $\mathbf{p}_{4, j}^{S}=[0,0.5,2,5,10]$.

The results of the CCTV survey were contained in the structural defects vector $\mathbf{f}^{S}$ :

$$
\mathbf{f}^{S}=\left(f_{1}^{S}, f_{2}^{S}, \ldots, f_{i}^{S}, \ldots, f_{m 1}^{S}\right)
$$

where: $f_{i}^{S}$ - component of vector $\mathbf{f}^{S}$ containing numerically determined sizes of $i$ sewer structural defects expressed, depending on the defect type, in $\mathrm{mm}, \mathrm{cm}^{2}$ or percents.

When matrix $\mathbf{P}^{S}$ and vector $\mathbf{f}^{S}$ are known, the values of structural defect category vector $\mathbf{c}^{S}$ may be established:

$$
\mathbf{c}^{S}=\left[c_{1}^{S}, c_{2}^{S}, \ldots, c_{i}^{S}, \ldots, c_{m 1}^{S}\right]
$$

where: $c_{i}^{S}$ - component of vector $\mathbf{c}^{S}$ equal to structural failure probability category for each $i$-th defect.

Ultimately, sewer structural failure probability category $p^{C S}$ for the structural safety criterion is equal to the highest numerical value among the components of vector $\mathbf{c}^{S}$.

The O\&M defects matrix $\mathbf{P}^{E}$ contains $m 2$ (here $m 2=10$ ) defects (described earlier as $\mathrm{e} 01, \mathrm{e} 02, \ldots \mathrm{e} 10)$ in $n 2=5 \mathrm{O} \& \mathrm{M}$ failure probability categories.

Category of probability $1 .(j=1)$, very unlikely (acceptable O\&M condition, failure as blockage, overflow of sewage, flooding and contamination of ground, groundwater or neighbouring areas, water infiltration, sewer exfiltration, or others, unlikely in the foreseeable future),

Category of probability 2. $(j=2)$, unlikely; minimal O\&M failure probability in the short term but potential for further deterioration.

Category of probability 3. $(j=3)$, somewhat likely; O\&M failure unlikely in the near future but further deterioration likely.

Category of probability 4. $(j=4)$, likely; O\&M failure likely in the near future.

Category of probability 5. $(j=5)$, highly likely; O\&M defects requiring immediate attention.

CCTV results were contained in O\&M defects vector $\mathbf{f}^{E}$ with $m 2$ components. Then the components of vector $\mathbf{c}^{E}$ were established to be equal to probability categories $j$ for each $i$-th O\&M defect. Analogously to the case of category $p^{C S}$, sewer O\&M failure probability category $p^{C E}$ was proposed for the environmental criterion, equal to the highest numerical value from among vector $\mathbf{c}^{E}$ components. 


\section{FREQUENCY OF FAILURE PROBABILITY CATEGORIES FOR SIX MOST OFTEN DETECTED DEFECTS}

Table 3 shows the percentage of vitrified clay sewer pipelines investigated at Kielce University of Technology in relation to each failure probability category for six most often detected defects: movable deposit, longitudinal cracks, radial and longitudinal displaced joints, post infiltration encrustation and tree roots growing into the sewer pipe.

Table 3

Frequency of defects in failure probability categories for six most common defects in vitrified clay sewers [\%]

\begin{tabular}{|l|c|c|c|c|c|}
\hline \multirow{2}{*}{ Defect } & \multicolumn{5}{|c|}{ Category of failure probability } \\
\cline { 2 - 6 } & I & II & III & IV & V \\
\hline e01 - movable deposits & 67.0 & 25.0 & 4.5 & 1.5 & 2.0 \\
\hline s02 - longitudinal cracks & 2.0 & 28.0 & 44.2 & 20.3 & 5.5 \\
\hline e09- radial displaced joint & 73.9 & 22.1 & 2.1 & 1.2 & 0.7 \\
\hline e10 - longitudinal displaced joint & 72.1 & 25.1 & 2.2 & 0.3 & 0.3 \\
\hline $\mathrm{e} 08$ - post infiltration encrustation & 85.5 & 14.2 & 0.3 & 0.0 & 0.0 \\
\hline $\mathrm{e} 03$ - roots of the tree growing into the sewer & 65.2 & 18.7 & 7.6 & 3.5 & 5.0 \\
\hline
\end{tabular}

The number of sewer sections classified under the highest failure probability category 5 is relatively small ranging from 0 to $5.5 \%$. The highest percentage of sewer sections in the range from 2.0 to $85.5 \%$ were classified in category 1 , the lowest category of sewer failure probability.

Numerical values of elements in matrix $\mathbf{P}^{E}$, similarly to those in matrix $\mathbf{P}^{S}$, were determined on the basis of the literature data $[1,7,13,14]$. For example, for roots of the tree growing into the sewer (e03), i.e., $i=3$ vector $\mathbf{p}_{3, j}^{E}$ expressed in percent is $[0,5,20$, $35,50]$. Depending on the ratio comparing the value of the cross section area of the sewer occupied by the roots with the total area of the sewer expressed in percentage, the sewer pipe can be classified under one of the following categories of failure probability:

- category 1 for $p_{3,1}^{E}<5$,

- category 2 for $5 \leq p_{3,2}^{E}<20$,

- category 3 for $20 \leq p_{3,3}^{E}<35$,

- category 4 for $35 \leq p_{3,4}^{E}<50$,

- category 5 for $p_{3,5}^{E}>50$.

The failure that results from the roots growing into the sewer may have the form of the flooding of sewers and laterals, backups in basements, flooding and contamination of neighboring areas, water infiltration to the inside of the sewer or sewage exfiltration to the soil and soil contamination. 
The failure caused by the roots growing into the sewer is highly likely in $5.0 \%$ of the investigated sections (Table 3). Failure probability is likely in $3.5 \%$ of segments, somewhat likely in $7.6 \%$ of sections and unlikely in $18.7 \%$ of investigated sections and very unlikely in $65.2 \%$ of the sewer sections.

When for example, the results from the investigation show that $f_{3}^{E}=40$ (tree roots occupy $40 \%$ of the sewer cross section), the category of the environmental failure due to ingrown roots is equal to $4\left(\mathrm{c}_{3}^{E}=4\right)$. Category $p^{C E}$ of the sewer failure probability is 4 in this case, unless any other of the remaining defects increases this category to 5 .

\section{CATEGORIES OF CONSEQUENCES OF THE SEWER FAILURES}

Because consequences of the failure of sewer pipelines including its blockage are related not only to the sewer technical condition parameters such as the sewer size, depth of cover, location, traffic intensity, etc. should be included in the analysis of the prioritization of sewer failure risk.

For instance, consequences of the collapse of a diameter DN $200 \mathrm{~mm}$ sewer laid in a shallow dry ground of a green area are not serious in comparison with the collapse of, for example a DN 2000 sewer laid deep in the ground, below the ground water table under a heavy-traffic city road. The proposed matrix $\mathbf{K}$ describes the consequences of the sewer failure:

$$
\mathbf{K}=\left|\begin{array}{cccccc}
k_{1,1} & k_{1,2} & \ldots & k_{1, j} & \ldots & k_{1, n} \\
k_{2,1} & k_{2,2} & \ldots & k_{2, j} & \ldots & k_{2, n} \\
\ldots & \ldots & \ldots & \ldots & \ldots & \ldots \\
k_{i, 1} & k_{i, 2} & \ldots & k_{i, j} & \ldots & k_{i, n} \\
\ldots & \ldots & \ldots & \ldots & \ldots & \ldots \\
k_{m, 1} & k_{m, 2} & \ldots & k_{m, j} & \ldots & k_{m, n}
\end{array}\right|
$$

where: $k_{i, j}$ - the element of the matrix of sewer failure consequences expressed in numerical values (mm, m, or numbers from 1 to 5 ), for the $i$-th factor and $j$-th category of consequence, $m$ - the number of factors affecting the consequences of sewer failure, $n$ - the number of consequence categories.

The matrix $\mathbf{K}$ covers $m=9$ factors: $i=1$, pipe size (circular pipe diameter or substitute diameter of non-circular pipe), containing lower boundary values, expressed in $\mathrm{mm}, i=2$, sewer burial depth, containing lower boundary values, expressed in $\mathrm{m}$, $i=3$, sewer function, expressed in numbers, $i=4$, sewer embedment against the ground water table, expressed in numbers, $i=5$, road type, expressed in numbers, $i=6$, traffic intensity, expressed in numbers, $i=7-$ land use and location, expressed in numbers, $i=8$, access for repair, expressed in numbers, $i=9$, environmental impact, expressed in numbers. 
Analyzed factors are grouped in $m=5$ categories of failure consequences: $j=1$, insignificant (negligible), $j=2$, minor (marginal), $j=3$, moderate (considerable), $j=4$, major (serious), $j=5$, catastrophic (very serious). The matrix were created based on the data found in the literature [15-17] and on the results of the author's analyses.

Numerical values for the analyzed sewer were contained in the sewer failure consequence vector $\mathbf{b}^{K}$ :

$$
\mathbf{b}^{K}=\left[\begin{array}{llllll}
b_{1}^{K} & b_{2}^{K} & \ldots & b_{i}^{K} & \ldots & b_{n}^{K}
\end{array}\right]
$$

where: $b_{i}^{K}$-component of the vector $\mathbf{b}^{K}$ containing numerical values of $i$-th factors from matrix $\mathbf{K}$.

When matrix $\mathbf{K}$ and vector $\mathbf{b}^{K}$ are known, the values of sewer failure consequence category vector $\mathbf{c}^{K}$ is established:

$$
\mathbf{c}^{K}=\left[\begin{array}{llllll}
c_{1}^{K} & c_{2}^{K} & \ldots & c_{i}^{K} & \ldots & c_{n}^{K}
\end{array}\right]
$$

where: $c_{i}^{K}$ - component of vector $\mathbf{c}^{K}$ containing numerical values of failure consequence categories in the range $1-5$ for successively $i=1,2, \ldots ., m$ factors.

Taking into account the decision-maker's preferences with regard to the significance of the analyzed factors, the measure of consequence of failure $k_{k}$ is calculated from the following formula:

$$
k_{k}=\frac{c_{i}^{K} w_{i}}{100}
$$

where: $w_{i}$ - component of the vector

$$
\mathbf{w}=\left[\begin{array}{llllll}
w_{1} & w_{2} & \ldots & w_{i} & \ldots & w_{m}
\end{array}\right]
$$

with percentage weights assigned successively to factors $i=1,2, \ldots, m$ of the matrix $\mathbf{K}$ assuming that $\sum_{i=1}^{m} w_{i}=100$.

Finally the following five categories of failure consequence were adopted:

- category 1 - negligible $\left(1 \leq k_{k} \leq 1.8\right)$,

- category 2 - marginal $\left(1.8<k_{k} \leq 2.6\right)$,

- category 3 - considerable $\left(2.6<k_{k} \leq 3.4\right)$,

- category 4 - serious $\left(3.4<k_{k} \leq 4.2\right)$,

- category 5 - very serious $\left(4.2<k_{k} \leq 5\right)$. 


\section{ENVIRONMENTAL AND STRUCTURAL SEWER FAILURE RISK}

Mathematically, risk is defined as its probability multiplied by the consequences of any given undesired event.

$$
\begin{aligned}
& r^{E}=p^{C E} k \\
& r^{S}=p^{C S} k
\end{aligned}
$$

where: $r^{E}, r^{S}$ - measures of environmental and structural failure risk, $p^{C E}, p^{C S}$ - measures of category of sewer failure probability for environmental and structural criterion, $k-$ measure of category of sewer failure consequences.

Matrices of environmental and structural failure risk $\mathbf{R}^{E}$ and $\mathbf{R}^{S}$ are proposed below:

$$
\begin{aligned}
& \mathbf{R}^{E}=\left\lfloor r_{i, j}^{E}\right\rfloor_{m \times n} \\
& \mathbf{R}^{S}=\left\lfloor r_{i, j}^{S}\right\rfloor_{m \times n}
\end{aligned}
$$

for $i=1,2, \ldots, m, j=1,2, \ldots, n$, where, $r_{i, j}^{E}, r_{i, j}^{S}$ - elements of the matrices of risk $\mathbf{R}^{E}$ and $\mathbf{R}^{S}$ for the $i$-th category of sewer failure probability and for $j$-th category of sewer failure consequence, $m$ - number of categories of sewer failure probability, $n$-number of categories of sewer failure consequences.

As proposed earlier, matrices $\mathbf{R}^{E}$ and $\mathbf{R}^{S}$ comprises five categories of sewer failure probability and five categories of sewer failure consequences. Figure 1 presents sewer failure risk matrix $\mathbf{R}^{E}$ or $\mathbf{R}^{S}$.

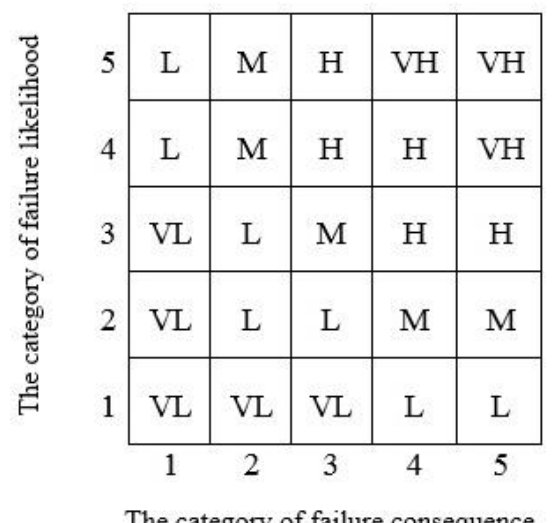

Fig. 1. Matrix of risk of sewer failure 
In the matrix $\mathbf{R}^{E}$, five classes of environmental failure risk were adopted with corresponding five groups of maintenance and repair (M\&R) procedures (mostly remove of sediment, cutting of roots, sealing of leaky joints) priority:

- risk very high $(\mathrm{VH}), R \geq 20-\mathrm{M} \& \mathrm{R}$ procedures priority immediate,

- risk high $(\mathrm{H}), 12 \leq R<20-\mathrm{M} \& \mathrm{R}$ procedures priority immediate high,

- risk medium (M), $8 \leq R<12-\mathrm{M} \& \mathrm{R}$ procedures priority medium low,

- risk low (L), $4 \leq R<8-\mathrm{M} \& \mathrm{R}$ procedures priority low,

- risk very low (VL), $R<4-$ no action required.

In the matrix $\mathbf{R}^{S}$, five classes of structural failure risk were adopted with corresponding five groups of rehabilitation (mostly trenchless rehabilitation: non-structural, semi structural or fully structural) priority:

- risk $\mathrm{VH}, R^{S} \geq 20$ - rehabilitation priority immediate,

- risk $\mathrm{H}, 12 \leq R^{S}<20$ - rehabilitation priority immediate high,

- risk $\mathrm{M}, 8 \leq R^{S}<12$ - rehabilitation priority medium low,

- risk L, $4 \leq R^{S}<8$ - rehabilitation priority low,

- risk VL, $R^{S}<4$ - rehabilitation not required.

\section{DISCUSSION}

The evaluation of environmental and structural safety of sewers is a complex and difficult issue.

The problem can arise due to a number of factors influencing environmental and structural safety of sewers, e.g.:

- sewer designers used different methods at various times and as a result the sewer initial factors of structural safety were divergent,

- strength parameters of sewers made of materials of the same type were different in different periods,

- by reason of gravity flow over flat terrain, sewers made of similar pipes are laid at different depths, thus their safety factors are varied along the pipe route,

- sewers with the same diameter were quite frequently built from pipes in different load capacity classes (e.g., vitrified clay pipes are typically produced in three classes of load capacity), having different safety factors depending on the section,

- sewers are laid with different longitudinal slopes, thus their bottoms are subject to different levels of abrasion and different accumulation of sediment,

- chemical composition of sewage and sediments determines their corrosive effect on the pipe walls similarly ground and water outside can affect the pipes in different ways,

- land use patterns change over time making new dead, and service loads act on the sewer in the ground, 
- as a result of ground rheological changes, the loads related to the ground weight can substantially decrease, but in some cases, they can increase, like when the ground outside the sewer destabilizes due to ground water infiltration into the sewer, or due to exfiltration of sewage from the sewer into the ground,

- workmanship quality might differ from section to section, embedment conditions were different (including type and angle of embedment), backfill condition (including degree of compaction and corresponding module of deformation), occasionally damaged pipes were used - all those variables had a considerable influence on the size of loads acting on the pipes.

The number of sewer environmental and structural safety-determining factors mentioned above confirms the thesis that the results of CCTV surveys showing sewer damage as a consequence of the joint action of those factors enable the reviewer to assess the probability of the sewer failure with the proposed method. Most research papers have recently focused exclusively on the sewer deterioration models. In this regard, it would be worthwhile to initiate new research efforts devoted to the evaluation of above mentioned factors. Sewer environmental safety analyses would also be important and should include the methods of eliminating the factors that restrict sewage flows, ensuring sewer water tightness and eliminating the phenomena of ground water infiltration into the sewers and sewage exfiltration into the ground. For the purpose of determining numerical parameters of matrices $\mathbf{P}^{S}$ and $\mathbf{P}^{E}$, a lot of effort was required to assign numerical ranges of the analyzed defects to particular categories of failure probability. The analyses proposed above would confirm or verify the adopted values of the said numerical parameters. An additional objective of those analyses would be the possibility of obtaining new, frequently left aside, relationships that exert a substantial influence on structural and environmental safety of sewers, e.g. the effect of rheological changes in the soil on the growth of the sewer safety factor. All currently available analyses assume that deterioration of sewers develops over time with the resultant decrease in the factor of safety.

The most important results of this paper include:

- A comprehensive and interdisciplinary approach to the issue of environmental and structural risk of long operated clay sewers.

- A proposal of methods for determining sewer failure probability and consequence with the risk matrix as a valuable tool for planning the sewer maintenance or trenchless rehabilitation procedures. The method helps to prioritize particular sewer sections in terms of environmental and structural safety from those of the highest risk to those of the lowest risk, which allows efficient sewer failure risk management.

- Determining numerical values for the proposed matrices based on author's analyses of long-term CCTV surveys, laboratory tests and field studies.

- Formulating important problems that affect sewer environmental and structural safety but are frequently overlooked in the available analyses of sewer deterioration issues. 


\section{CONCLUSIONS}

Two kinds of defects, linear and spot, occur in vitrified clay sewer pipes long time in operation. These defects have been divided into two groups: those affecting the environmental hazards of the sewer pipes and those affecting the structural integrity. The former comprise: movable deposits, solid deposits, roots of the tree growing into the sewer, a lateral intruding into the sewer, other external pipelines built through the sewer wall or improper connection, for example, the connection of sanitary sewage laterals into storm water sewers, infiltration of the groundwater into the leaky sewer, sealing rings intruding into sewer, post infiltration encrustation, radial and longitudinal displaced joints of the pipes. The latter group of defects that affect structural hazards of the sewer pipe comprises: abrasion of the sewer bottom, longitudinal cracks, circumferential cracks, multiple cracks, missing pieces of the sewer wall, deformation or collapse of the rigid sewer.

Quantitative analysis of sewer defects indicates that movable deposits (60.23\%) were the most frequently detected linear defect affecting the environmental hazards of the sewer pipe. The most frequent spot defects included radial displaced joints (17.95 defects $/ 100 \mathrm{~m})$, longitudinal displaced joints $(12.15$ defects $/ 100 \mathrm{~m})$, post infiltration encrustation $(7.82$ defects $/ 100 \mathrm{~m})$, roots of the tree growing into the sewer (3.99 defects $/ 100 \mathrm{~m})$ and infiltration of the groundwater into the leaky sewer $(1.48$ defects $/ 100 \mathrm{~m})$.

Quantitative analysis of sewer defects indicates that the most frequently detected defects that have an influence on the structural safety of the sewer pipe included longitudinal cracks (1.96\%) among the linear defects type, and multiple cracks (2.01 defects $/ 100 \mathrm{~m})$ and missing pieces of the sewer wall $(1.28$ defects $/ 100 \mathrm{~m})$ among the spot defect type.

The causes of the defects observed in the investigated sewer pipes have been summarized in five groups: faulty design, improper materials, defective workmanship, incorrect service and external factors that occurred during operation of the sewer.

CCTV method enabled quick inspection of the inside of the sewer and recording detected defects. The type and size of the defects; as proved in this paper, enable predicting failure probability for the inspected pipes. The method proposed in this paper makes it possible to determine the sewer failure probability category. The method classifies each section of the sewer to one of five failure probability categories, analyzed separately for environmental and structural integrity hazards. The proposed method contains the matrix of sewer failure consequences and finally two matrices of risk for environmental and structural hazards. The sewers included in the highest risk category should be scheduled for rehabilitation or adequate M\&R procedures as the priority sections of sewers. In cases where structural defects has been detected, rehabilitation or replacement (mainly by a trenchless method) method have to be implemented. The strategy for $O \& M$ defects prevention should include various procedures of elimination operational defects, for example cleaning, sealing, clearing the ingrown roots, etc. 


\section{REFERENCES}

[1] Water Authorities Association, Sewerage Rehabilitation Manual, Vol. 1-3, Water Research Centre, Swindon 1990.

[2] Zayed T., Salman A., Basha I., The impact on environment of underground infrastructure utility work, Struct. Infrastruct. E., 2012, 3 (7), 199.

[3] KuliczKowski A., KuliczKowska E., KUBicka U., The criterions of urgency for sewerline rehabilitation, [in:] Proc. No-Dig Conference, NASTT, Chicago, Illinois, 2010, Paper A-4-05.

[4] KutYŁowska M., Hotloś H., History, structure and deterioration of sewerage system in Wrocław, Environ. Prot. Eng., 2012, 38 (3), 145.

[5] VeldhUis J., Clemens F., VAN GELDER P., Quantitative fault tree analysis for urban water infrastructure flooding, Struct. Infrastruct. E., 2011, 11 (7), 809.

[6] KuliczKowsKa E., Criteria of planning the trenchless renewal of non-entry sewers, University of Technology Kielce Press, Kielce 2008 (in Polish).

[7] ATV-Information, Condition of sewers in Germany, ATV Press, Hennef 2011 (in German).

[8] Berger C., FAlk C., Condition of sewers in Germany, Deutsche Vereinigung für Wasserwirtschaft, Abwasser und Abfall e.V. Press, Hennef 2011 (in German).

[9] Kolonko A., Kotowski A., Proecological technologies of sewers rehabilitation, Environ. Prot. Eng., 2007, 33 (4), 55.

[10] Hill N., Sanitary System Asset Management Plan, District of West Vancouver, Final Report, No. 111319 (60118812) AECOM Canada, 2010.

[11] Albin R.L., Kinshella P.E., Accelerated corrorion rate threatens Phoenix sewers, [in:] Proc. No-Dig Conference, NASTT, New Orleans, Louisiana, 2004, Paper F-4-03.

[12] Kuliczkowski A., Kuliczkowska E., PARKa A., Field measurements of sewer main structural integrity, [in:] Proc. No-Dig Conference, NASTT, Washington, DC, 2011, Paper E-3-04.

[13] Per Aarsleff, Inspection of sewer pipes using CCTV. Basic definitions and manual photographic, Warsaw, 1989 (in Polish).

[14] Stichting Rioned, Cataloque of sewer defects, Ede, 1998.

[15] LukAS A., Merrrill M., Scraps, an expert system for prioritizing sewer inspections, [in:] Proc. No-Dig Conference, NASTT, Nashville, TN, 2006, Paper A-4-03.

[16] MCDonald S., ZHAO J., Condition assessment and rehabilitation of large sewers, Report No. NRCC-44696, Institute for Research in Construction, National Research Council, Ottawa 2001.

[17] SARRAMI K, LOSTRACCO S., Implementing an infrastructure asset management program to the city of Toronto, [in:] Proc. No-Dig Conference, NASTT, Montreal 2002. 